\title{
The Effect of Cyclic Torsion on the Dislocation Structure of Drawn Mild Steel
}

\author{
Maria Teresa Paulino Aguilar ${ }^{\mathrm{a} *}$, Elaine Carballo Siqueira Corrêa ${ }^{\mathrm{b} *}$, \\ Waldemar Alfredo Monteiro ${ }^{\mathrm{c}}$, Paulo Roberto Cetlin ${ }^{\mathrm{b}}$
}

\author{
a'Materials Engineering and Construction Department, Universidade Federal de Minas Gerais, \\ Rua Espírito Santo, 35, Centro, 30160-030 Belo Horizonte - MG, Brazil \\ ${ }^{\mathrm{b}}$ Metallurgical Engineering Department, Universidade Federal de Minas Gerais, \\ Rua Espírito Santo, 35, Centro, 30160-030 Belo Horizonte - MG, Brazil \\ ${ }^{\mathrm{c}}$ Materials Engineering Department, Nuclear and Energetic Research Institute, \\ Cidade Universitária Armando Salles, 0508-900 São Paulo - SP, Brazil
}

Received: May 16, 2006; Revised: July 31, 2006

\begin{abstract}
Cold forming is usually associated with the "work hardening" of the material being formed. The work hardening behavior of metals subject to complex processing paths is different from that in monotonic deformation. The results show that, after some initial hardening, there is a possibility that further deformation will cause softening in the material ("work softening"). Recent work showed that cyclic torsion applied to drawn products causes changes in the subsequent tensile behavior of low carbon steel, and that the effect will depend on the previous "history" of the material. For annealed samples, the cyclic torsion leads to an increase in the yield strength, but does not affect the tensile strength and elongation. For the case of previously drawn bars, the cyclic deformation caused a decrease in the yield and tensile strength and an increase in the total elongation. The present paper discusses the dislocation structure changes associated with different strain paths in mild steel.
\end{abstract}

Keywords: dislocation structures, cyclic torsion, drawing

\section{Introduction}

Cold forming of metals usually causes their work hardening. The magnitude of this hardening depends on the area reduction, on the temperature and strain rate associated with the processing, and on the way the strain is imposed on the metal. Keeping all other variables constant, the work hardening of a metal submitted to a sequential straining under varying directions or of different natures is different from that resulting from monotonic straining. Changes in the way the material is deformed can alter the hardening rates and even cause strain softening of the metal ${ }^{1-16}$.

Recent research results ${ }^{17-19}$ show that cyclic straining influences in various ways the mechanical behavior of annealed and drawn metal bars. Annealed Aluminum submitted to cyclic torsion displays higher flow stresses than the annealed material. On the other hand, cyclic torsion softens previously drawn Aluminum. Cyclic torsion also softens steel bars previously drawn in one or two passes and hardens the initially annealed material. Experimental results indicate that the stress-strain curve and the work hardening coefficient (n) of steel drawn in two passes and submitted to cyclic torsion are similar to those for the material submitted to only one drawing pass. This is similar to the case of the Aluminum alloy 6063, where the cyclic torsion after two drawing passes eliminates the hardening associated with the second drawing pass. It is also observed for both materials that their Ultimate Tensile Strength (UTS) tends to remain unaltered by cyclic torsion, in the case of initially annealed material, whereas their Yield Strength (YS) is considerably increased by cyclic torsion. The YS and UTS of both previously drawn materials are decreased by cyclic torsion, with the exception of the YS of Aluminum drawn in a single pass. The decrease in these properties is more pronounced after two drawing passes than after a single drawing pass. Finally, cyclic torsion increases the Tensile Elongation to Fracture of drawn material and decreases this property for initially annealed material.

The present research analyzes the relationship between the mechanical effects described above and the dislocation structures in Low Carbon steel.

\section{Materials and Experimental Methods}

The material was an AISI 1010 steel with the following chemical composition: $0.12 \% \mathrm{C}, 0.47 \% \mathrm{Mn}, 0.07 \% \mathrm{Si}, 0.003 \% \mathrm{Sn}, 0.01 \% \mathrm{Mo}$, $0.016 \% \mathrm{Pe} 0.013 \% \mathrm{~S}$, received as cylindrical bars $6.4 \mathrm{~mm}$ in diameter. The bars were initially annealed and some of them were drawn in one or two passes. A fraction of these bars were then submitted to cyclic torsion. The effects of the strain path were analyzed by Transmission Electron Microscopy (TEM).

Annealing was performed under vacuum, at $850^{\circ} \mathrm{C}$ for $2400 \mathrm{sec}-$ onds, leading to an average hardness of $122.6 \mathrm{HV}$. Drawing was performed in a hydraulic draw bench, using Tungsten Carbide dies with semi-angle of $8^{\circ}$ and abundant lubrication with a Molybdenum Disulfide paste. Different dies were employed, guaranteeing a fixed reduction of area of $20 \%$ in each pass. Cyclic torsion (11.2\% plastic strain per cycle, total of 10 cycles) was performed in an especially adapted lathe, where the chuck was manually actuated. All experiments were performed at room temperature, at a strain rate of $0.002 / \mathrm{s}^{5}$. All deformed samples were stored at temperatures below $0{ }^{\circ} \mathrm{C}$ in order to avoid static strain aging effects.

TEM was performed in a JEOL-JEM microscope, operated at $200 \mathrm{kV}$. Analyses were performed in $3 \mathrm{~mm}$ samples taken from the cross-section of the bars. Sample preparation involved initial mechani- 
cal polishing, followed by electrolytic thinning with a perchloric acid and ethanol solution at room temperature.

\section{Results and Discussion}

The dislocation structures of the annealed and of the drawn material (in one or two passes) are shown in Figures 1 and 2 respectively. The dislocation density is quite low for the annealed material, whereas the deformed material displays a much higher dislocation density. Drawn material shows an aligned cell structure, with irregular cell sizes and cell wall thickness. Dense dislocation networks can be observed inside the cells. Higher drawing strains lead to a smaller cell size, as expected.

The dislocation structure of the material submitted only to cyclic torsion is broadly similar to that resulting from drawing (see Figure 3), but the cell size is higher and the tendency to cell alignment is less pronounced than in drawing. It is important to realize that the total strain caused by cyclic torsion is much higher than in drawing, but leads to essentially similar dislocation structures.

The analysis of Figure 4 indicates that the dislocation structure of the material after one drawing pass is altered by subsequent cyclic torsion. There is an increase in the cell size, a decrease in their alignment and in the dislocation density within the cells, and an overall evolution of alignment in only one direction to a "checkerboard" appearance, which is typical of the development of two sets of aligned cells, corresponding to the two directions of twisting. This is also the situation for the material initially annealed, drawn in 2 passes and cyclically twisted (Figure 5). Under these circumstances, the dislocation cells tend to be larger and the dislocation density inside the cells lower than for one drawing pass followed by cyclic torsion. Cyclic torsion promotes dynamic recovery of the material, involving the annihilation of cell walls and the decrease of dislocation density inside the cells. This is similar to results from the analysis of the Bauschinger effect ${ }^{20}$, where such dislocation annihilation stems from dislocation movements in opposing directions.

Considering the widely established relationship between the material flow stress $\Gamma$, and the corresponding dislocation density $\rho^{20}$ :

$$
\Gamma \propto \rho^{1 / 2}
$$

one should expect higher flow stresses in the drawn or cyclic twisted material than in the annealed material. On the other hand, the recovery

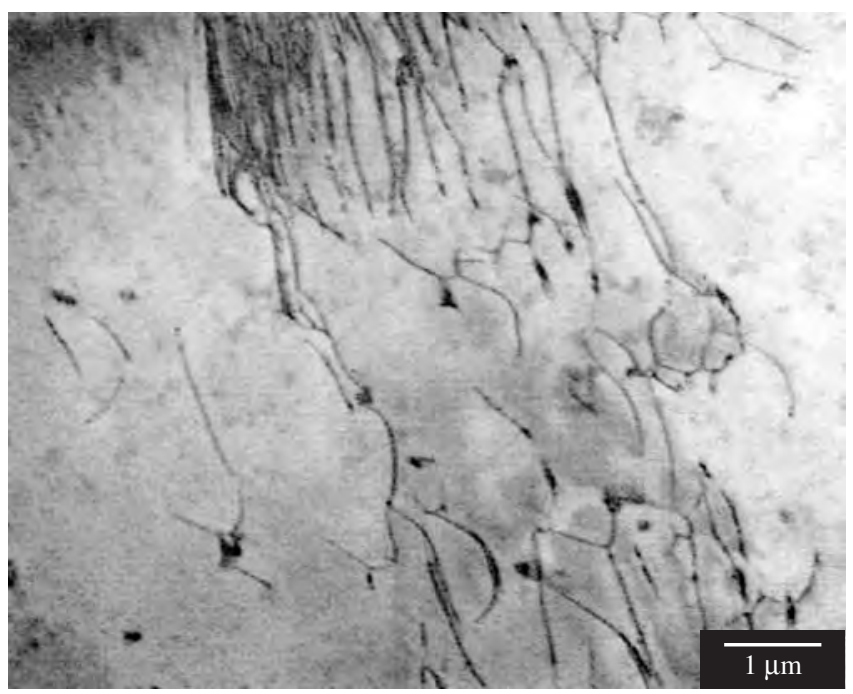

Figure 1. TEM of annealed steel.

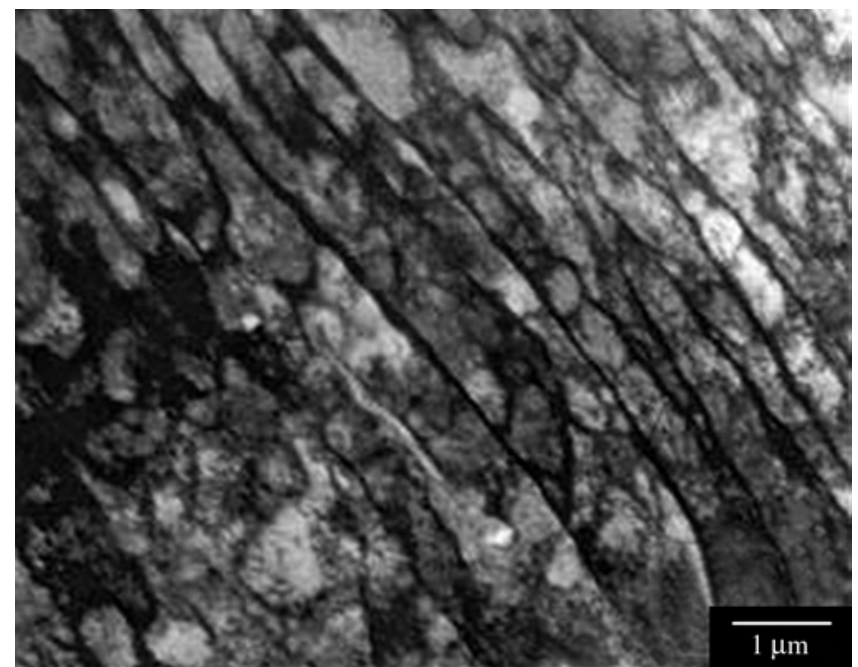

(a)

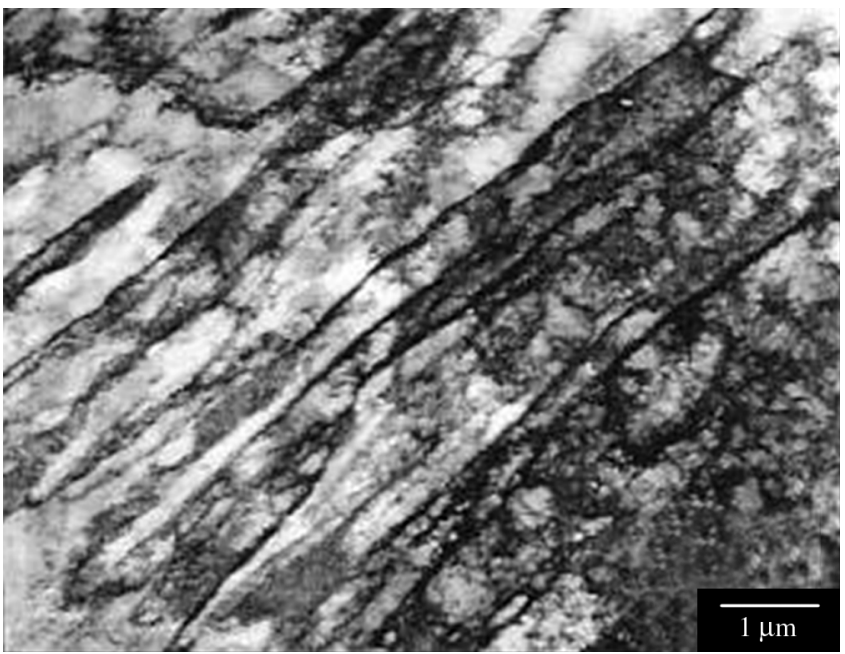

(b)

Figure 2. TEM of annealed and drawn steel ( $8^{\circ}$ and $20 \%$ per pass): a) 1 pass; and b) 2 passes.

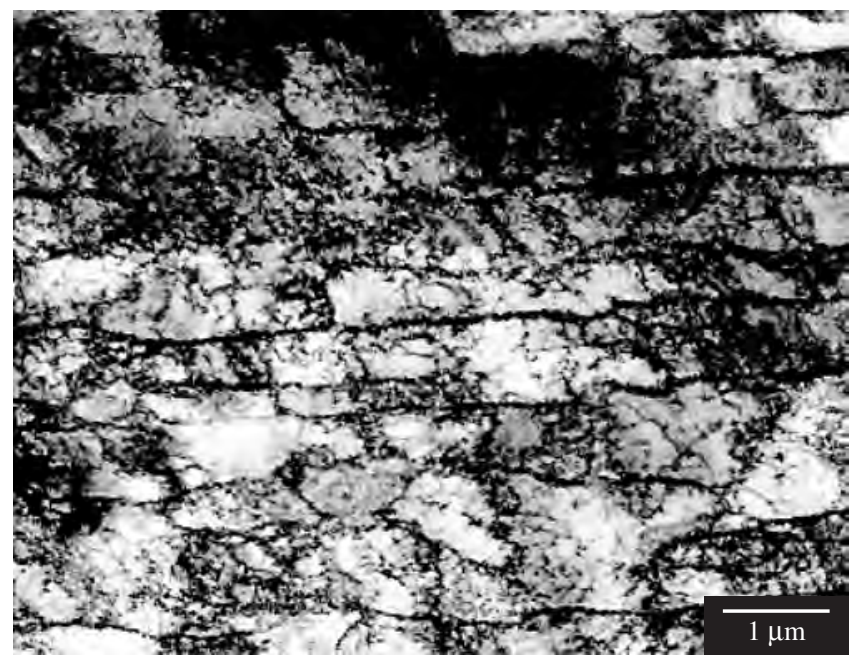

Figure 3. TEM of annealed steel submitted only to cyclic torsion $(11.2 \%$ strain per cycle, 10 cycles). 


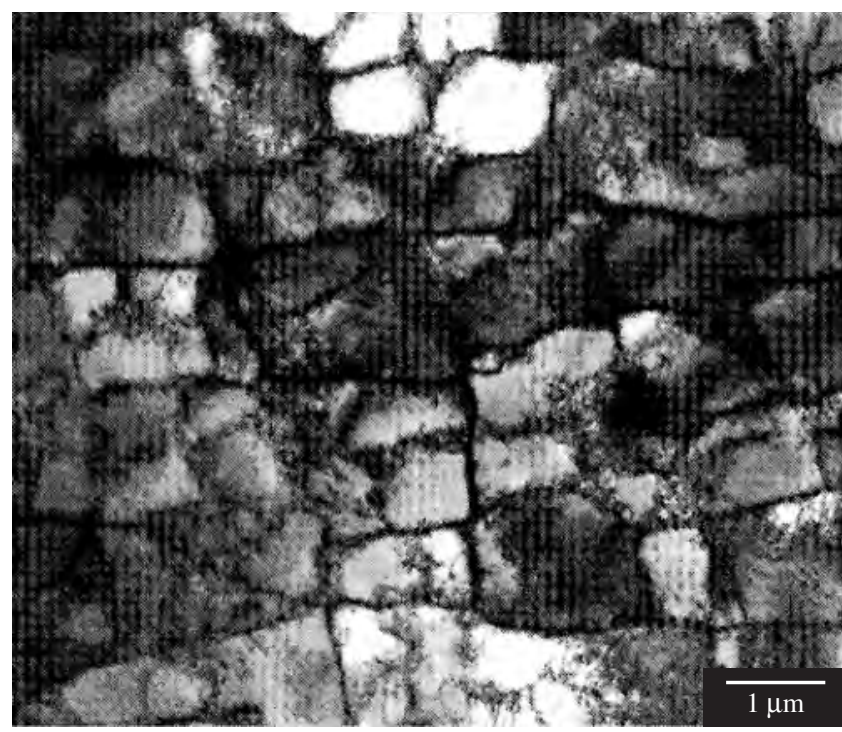

(a)

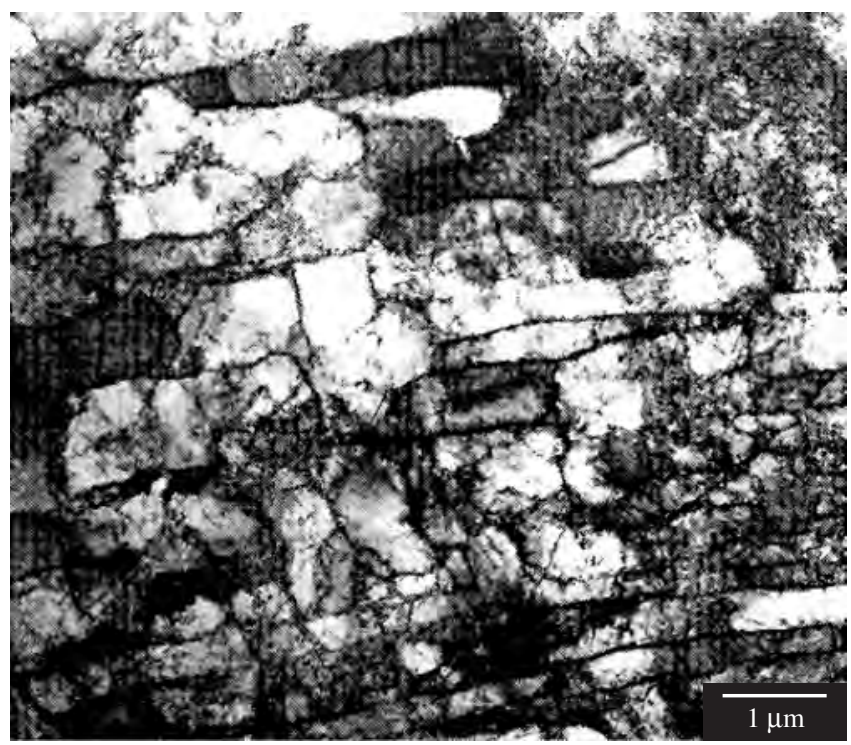

(b)

Figure 4. TEM of different regions of steel drawn in 1 pass ( $8^{\circ}$ e $\left.20 \%\right)$, and cyclically twisted (11.2\% per cycle, 10 cycles)

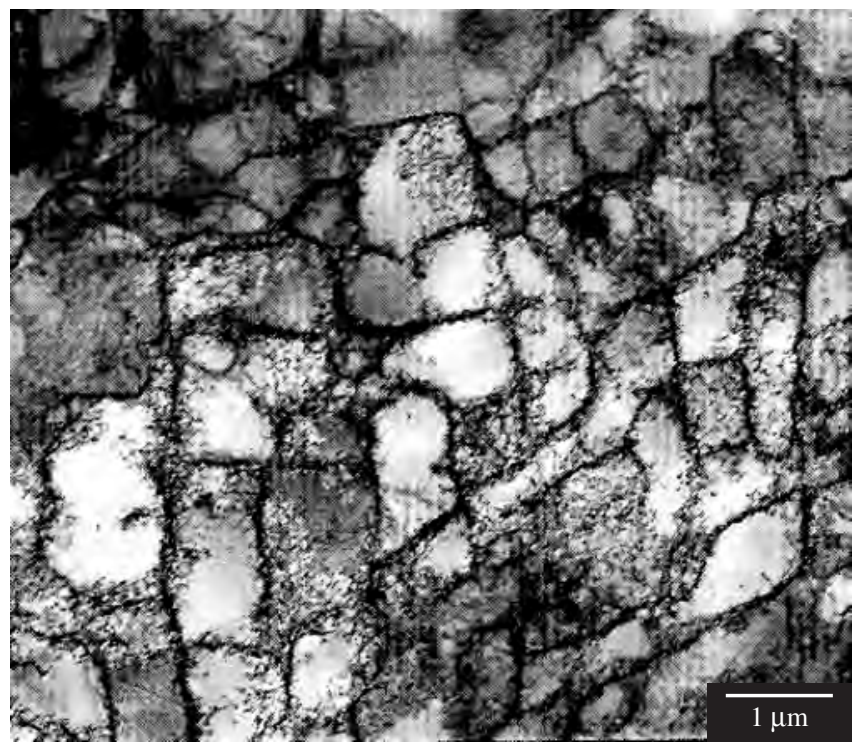

(a)

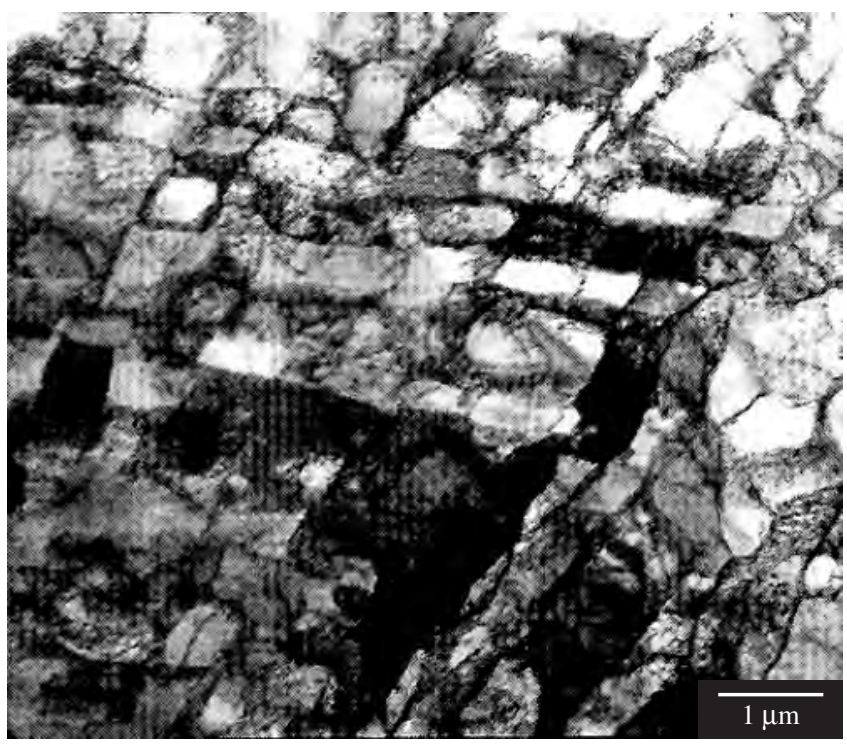

(b)

Figure 5. TEM of different regions of steel drawn in 2 passes ( $8^{\circ}$ e $\left.20 \%\right)$, and cyclically twisted (11.2\% per cycle, 10 cycles)

promoted by cyclic torsion of the previously drawn material should lead to their softening and consequent lower flow stresses.

\section{Conclusions}

Drawing of low carbon steel leads to the formation of an aligned dislocation structure, displaying irregular cell sizes and cell wall thickness as well as dense networks of dislocations inside the cells.

Cyclic torsion promotes the softening of material previously strained by drawing. This softening is associated with a restructuring of the previous dislocation arrangement, involving an increase in cell size, a decrease in the dislocation density inside the cells and a "checkerboard" dislocation wall structure.

\section{Acknowledgments}

The authors are grateful to FAPEMIG (Fundação de Amparo à Pesquisa de Minas Gerais), to CNPq (Conselho Nacional de Desenvolvimento Científico e Tecnológico) and to PRONEX - MCT (Ministério da Ciência e Tecnologia) for the financial support of the present activities.

\section{References}

1. Armstrong PE, Hocket JE, Sherby OD. Large Strain Multidirectional Deformation of 100 Aluminum at 300K. Journal of the Mechanics and Physics of Solids. 1982; 30:37-58. 
2. Backofen WA, Ghosh AK. Strain Hardening and Instability in Biaxially Streched Sheets. Metallurgical Transactions, 1973; 4:1113-1123.

3. Coffin LF, Tavernelli JF. The Cyclic Straining and Fatigue of Metals. Transactions of the Metallurgical Society of AIME. 1959; 215:784-807.

4. Laukonis JV, Ghosh AK. Effects of Strain Path Changes on the Formability of Sheet Metals. Metallurgical Transactions. 1978; 9(A):1849-1856.

5. Longo WP, Reed-Hill RE. Work Softening in Dynamic Strain Aged Low Carbon Steel. Scripta Metallurgica. 1972; 6(9):833-836.

6. Polakowski NH, Palchoudhuri A. Softening of Certain Cold-Worked Metals under the Action of Fatigue Loads. Proceedings, American Society for Testing and Materials - ASTM. 1954; 54:701-716.

7. Sillekens WH, Dautzenberg JH, Kals JAG. Strain Path Dependence of Flow Curves. Annals of the College International pour la Recherche en Productique - CIRP. 1991; 40:255-258.

8. Thomsen EG. Stress-Strain Properties of Tough-Pitch Copper After Multi-Pass Drawing and Extruding. Transactions of the ASME - Journal of Engineering Materials and Technology. 1983; 105:178-181.

9. Wagoner RH. Plastic Behavior of 70/30 Brass Sheet. Metallurgical Transactions. 1982; 13(A):1491-1500.

10. Wilson DV, Zandrahmi M, Roberts WT. Effects of Changes in Strain Path on Work Hardening in CP Aluminium and an Al-Cu-Mg Alloy. Acta Metallurgica et Materialia. 1983; 38(2):215-226.

11. Rauch EF, Gracio JJ, Barlat F, Lopes AB, Duarte JF. Hardening Behavior and Structural Evolution Upon Strain Reversal of Aluminum Alloys. Scripta Materialia. 2002; 46:881-886.

12. Barlat F, Ferreira Duarte JM, Gracio JJ, Lopes AB, Rauch EF. Plastic Flow for Non-Monotonic Loading Conditions of an Aluminum Alloy Sheet Sample. International Journal of Plasticity. 2003; 19:1215-1244.
13. Kusnierz J, Kurowski M, Baliga W. Strain Softening Effects in Microstructure of Twisted Pre-Deformed Copper Rods. Materials Chemistry and Physics. 2003; 81:548-551.

14. Peeters B, Bacroix B, Teodosiu C, Van Houtte P, Aernoudt E. Work Hardening/Softening Behaviour of B.C.C. Polycrystals During Changing Strain Paths: II. TEM Observations of Dislocation Sheets in an IF Steel During Two-Stage Strain Paths and their Representation in Terms of Dislocation Densities. Acta Materialia. 2001; 49:1621-1632.

15. Langlois L, Berveiller M. Overall Softening and Anisotropy Related with the Formation and Evolution of Dislocation Cell Structures. International Journal of Plasticity. 2003; 19:599-624.

16. Gracio JJ, Lopes AB, Rauch EF. Analysis of Plastic Instability in Commercially Pure Al Alloys. Journal of Materials Processing Technology. 2000; 103:160-164.

17. Aguilar MTP, Corrêa ECS, Monteiro WA, Ferreira NAM, Cetlin PR. Work Softening of Drawn Low Carbon Steel Bars. Materials Research. 2001; 4:87-91.

18. Cetlin PR, Aguilar MTP, Corrêa ECS, Valle PE, Rezende JLL. Influence of Strain Path in the Mechanical Properties of Drawn Aluminium Alloy Bars. Journal of Materials Processing Tecnology. 1998; 80-81:376-379.

19. Corrêa ECS, Aguilar MTP, Monteiro WA, Cetlin PR. Work Hadening Behavior of Prestrained Steel in Tensile and Torsion Tests. Journal of the Materials Sience Letters. 2000; 19:779-781.

20. Dieter G E. Metalurgia Mecânica. 2 ed. Rio de Janeiro: Guanabara Dois; 1981. 